onism of constituted diabetics is quite unknown. However, if it can finally be proved that the synalbumin antagonist is in fact the ' $B$ ' chain of insulin, then the basic abnormality of essential diabetics which results in excessive circulating ' $B$ ' chain bound to albumin needs to be elucidated. Several possibilities exist:

(1) Decreased breakdown in the periphery of the albumin-bound ' $B$ ' chain.

(2) Increased ' $B$ ' chain production in the pancreas as a result of some abnormality of insulin production.

(3) Alteration in the hepatic or peripheral degradation of insulin, resulting in excess ' $B$ ' chain available for binding to albumin.

(4) A subtle change in the structure of diabetic albumin allowing it to carry larger quantities of 'B' chain.

\section{References}

Ensinck, J.W., CoOmbs, G.J., Williams, R.H. \& VallanceOWEN, J. (1964) Studies in vitro of the transport of the A and B chains of insulin in serum. J. biol. Chem. 239, 3377.
Ensinck, J.W., Mahler, R.J. \& Vallance-OWen, J. (1965) Antagonism of insulin action on muscle by the albuminbound B-chain of insulin. Biochem. J. 94, 150.

MIRSKY, I.A. \& BROH-KAHN, R.H. (1949) The inactivation of insulin by tissue extracts. I. The distribution and properties of insulin inactivating extracts (Insulinase). Arch. Biochem. 20, 1.

TomizaWA, H.H. \& HALSEY, Y.D. (1959) Isolation of an insulin-degrading enzyme from beef liver. J. biol. Chem. 234, 307.

VALlANCE-OWEN, J. (1962) Diabetes mellitus-Causation. Proc. roy. Soc. Med. 55, 207.

Vallance-OWen, J. (1964) Synalbumin insulin antagonism and diabetes. Ciba Fdn Colloq. Endocr. 15, 217.

Vallance-OWen, J. (1966) The inheritance of essential diabetes mellitus from studies of the synalbumin insulin antagonist. Diabetologia, 2, 248.

Vallance-Owen, J., Dennes, E. \& Campbell, P.N. (1958a) Insulin antagonism in plasma of diabetic patients and normal subjects. Lancet, ii, 336.

Vallance-Owen, J., Dennes, E. \& Campbell, P.N. (1958b) The nature of the insulin antagonist associated with plasma albumin. Lancet, ii, 696.

Vallance-Owen, J., Hurlock, B. \& Please, N.W. (1955) Plasma insulin activity in diabetes mellitus measured by the rat diaphragm technique. Lancet, ii, 583.

VallanCe-OWEN, J. \& Lilley, M.D. (1961) An insulin antagonist associated with plasma-albumin. Lancet, $\mathbf{i}, 804$.

\title{
Regional differences in the lung
}

\author{
JOHN B. WeST \\ Clinical Respiratory Physiology Research Group, \\ Royal Postgraduate Medical School, London
}

IN OCTOBER 1957, Dr M. Ter-Pogossian of St Louis, U.S.A., visited Hammersmith Hospital and demonstrated the use of a new radioisotope for biological research, oxygen-15, half-life $2 \mathrm{~min}$. Air was blown through the beam of the M.R.C. cyclotron and collected in a bag. Dr Ter-Pogossian took a breath of this: a counter at his finger-tips registered radioactivity within seconds. At the subsequent colloquium arranged by the M.R.C. Radiotherapeutic Research Unit, Professor McMichael was enthusiastic about the potential of this new tool and the active research programme using radioactive gases which has developed owes much to his support.

It was soon realized that marked differences in blood flow and ventilation as measured with radioactive oxygen exist between the top and bottom of the lung. At this time, very little was known about topographical differences within the lung; a well-known textbook of respiratory physiology devoted three lines to the subject! However, in the last 10 years it has been shown that there are great regional differences of blood flow, ventilation, gas exchange and morphology in the lung, and that these frequently have important clinical implications. In this short article it is only possible to give a brief summary of some of these advances.

\section{Blood flow}

When a subject inhales radioactive oxygen and holds his breath, the rate of removal of radioactivity from any region of the lung as measured with external counters is a measure of the local blood flow. In practice, oxygen-labelled carbon dioxide is a more useful gas because its removal by the blood flow is faster. The same information can be obtained using the reactor-produced radioactive gas xenon-133 and since this has a half-life of 5 days, it is a more convenient technique and is in general use throughout the world.

In the normal upright lung, blood flow is found to decrease rapidly from the bottom to the top reaching low values at the apex (Fig. 1) 
(West \& Dollery, 1960 ; Ball et al., 1962). This normal distribution is affected by change of posture and exercise. When a normal subject lies supine, apical and basal blood flow become the same, but a gradient of blood flow can be demonstrated between the front and back. On exercise, apical blood flow increases more than basal flow so that the distribution becomes more uniform. Both heart and lung disease usually alter the normal distribution of blood flow.

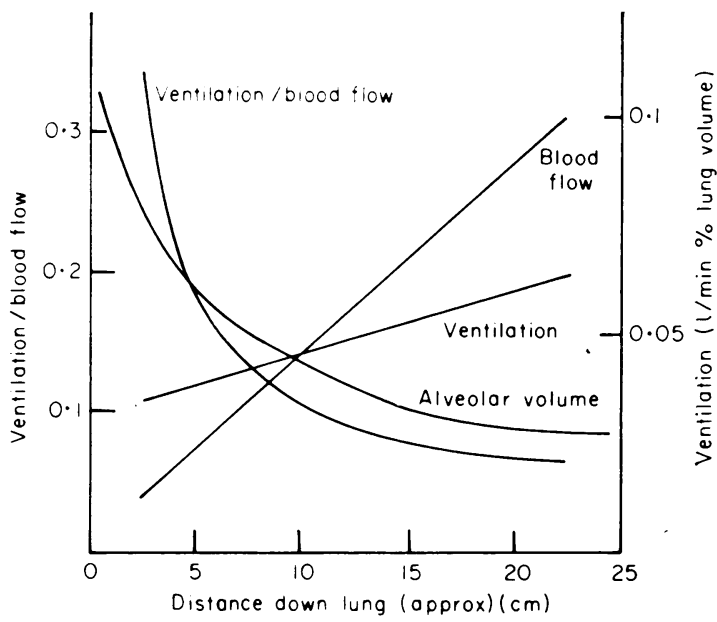

FIG. 1. Some of the regional differences in the lung. Blood flow increases rapidly from apex to base but ventilation changes more slowly. As a result, the ratio of ventilation to blood flow changes down the lung. These measurements were made with radioactive gases. The differences in alveolar volume shown are based on histological measurements on frozen dog lungs (arbitrary units).

Considerable effort has been devoted to the causes of these large topographical differences and it is now generally accepted that they can be explained by the hydrostatic pressures in the pulmonary blood vessels. At the bottom of the lung, the pulmonary artery pressure is some $25 \mathrm{cmH}_{2} \mathrm{O}(18 \mathrm{mmHg})$ higher than at the top because of the hydrostatic gradient, whereas the pressure outside the capillaries (approximately alveolar) is identical throughout the lung. It is known that the driving pressure responsible for flow in the upper regions is arterial minus alveolar pressure so that this increases down the lung. Moreover, the pressure tending to open up and distend the small vessels is much greater at the bottom of the lung than the top. Both these mechanisms contribute to the rapid increase in flow down the lung and it is not necessary to invoke any regulatory control.
A recent interesting finding has been the role of the larger pulmonary vessels (above $100 \mu$ diameter) in affecting vascular resistance in the lower parts of the lung (Hughes et al., 1967). It has been shown that these so-called extra-alveolar vessels are held open by the expansion of the lung, and that since the base of the upright lung is relatively poorly expanded (see below), these vessels significantly reduce blood flow in the lower zones. In addition any increase in interstitial pressure around these vessels as occurs when the pulmonary venous pressure is raised, further increases their vascular resistance. This process may result in an inversion of the normal distribution of blood flow in patients with severe mitral stenosis or left ventricular failure, so that apical blood actually exceeds basal blood flow.

\section{Ventilation}

Ventilation, that is the amount of inspired air going to any region of the lung, also increases down the lung but less rapidly than blood flow under normal conditions (Fig. 1). It is found that the way the lung ventilates depends very much on its initial volume (Milic-Emili et al., 1966). If a subject inspires slowly after a full expiration, initially all the gas goes to the upper zones and the base of the lung does not ventilate at all. However, after a certain lung volume has been reached, the lower zones ventilate better than the upper, and this is the case under normal breathing conditions.

The cause of these regional differences in ventilation is to do with the way the lung is supported inside the chest. There is evidence that the hilum takes very little of the weight of the lung, the brunt being borne by the pleural surface. As a consequence, the lower regions are relatively compressed by the weight of the lung above, and the upper zones are relatively overexpanded by the pull of the lung below. These differences are reflected in the intra-pleural pressure which has been shown to be less negative at the bottom of the upright lung.

Because the lower regions are so compressed at very low lung volumes, some expansion of the upper zones must occur before the lower zones can distend. An analogy is a loosely coiled vertical spring ('slinky') which is partly supported by a hand above and a table below. With small extensions, the lower coils remain together and only separate (ventilate) if the spring is considerably stretched. However, at high lung volumes the ventilatory behaviour is different. Now the upper regions are so far expanded that further distension is difficult, and as a result, the bulk of the inspired air goes to the lower zones. 


\section{Ventilation/blood flow}

One important consequence of the uneven distribution of blood flow and ventilation in the lung is its effect on gas exchange. Here the key factor is the ratio of ventilation to blood flow since this has been shown to determine the gas exchange which occurs in any region of the lung.

Because blood flow increases much more rapidly than ventilation down the lung, the ratio of ventilation to blood flow is high at the top of the lung but low at the bottom (Fig. 1). As a consequence, striking differences in regional gas exchange can be predicted, oxygen tension decreasing by over $40 \mathrm{mmHg}$ from the top to the bottom of the lung, and carbon dioxide tension increasing by some $14 \mathrm{mmHg}$ over the same distance. Large regional differences in the gas composition of the blood in the lung, and in the volumes of oxygen and carbon dioxide exchanged at various levels also occur.

Oddly enough, the overall ability of the lung to exchange gas between inspired air and pulmonary capillary blood is little affected by these regional differences under normal conditions. However, if the distribution of blood flow becomes more uneven, as a result of a fall in pulmonary arterial pressure or a rise in alveolar pressure for example, or if ventilation becomes more non-uniform, serious impairment of gas exchange may ensue. Examples of conditions in which this may occur are anaesthesia, positive pressure breathing, oligaemic shock, and exposure to high accelerations (West, 1965).

\section{Morphology}

We have seen that the topographical inequality of ventilation depends on the different relative expansions of the upper and lower regions of the lung. Recently it has been possible to demonstrate regional differences in alveolar size directly by freezing dogs intact and measuring alveolar size in the freeze-dried lung (Glazier et al., 1967). The results showed that in the vertical (head up) dog, the alveoli at the apex were approximately four times the volume of those at the base. However, when the animal was supine, the apex and base were the same whereas differences occurred between the ventral and dorsal aspects. The regional differences in alveolar size were abolished at high lung volumes.

One important consequence of these large inequalities is that the smallest alveoli in the dependent zones will be the most unstable and the first to collapse during prolonged shallow breathing or general anaesthesia. With the bulk of the lung perfusion going to the lower zones, gas exchange would then be seriously impaired.

\section{Acknowledgment}

I would like to acknowledge the help of my colleagues $\mathrm{Dr}$ J. B. Glazier, Dr J. M. B. Hughes and Dr J. E. Maloney.

\section{References}

Ball, W.C., Stewart, P.B., Newsham, L.G.S. \& Bates D.V. (1962) Regional pulmonary function studies with xenon $^{138}$. J. clin. Invest. 41, 518.

Glazier, J.B., Hughes, J.M.B., Maloney, J.E. \& West, J.B. (1967) Vertical gradient of alveolar size in lungs of dogs frozen intact. J. appl. Physiol. (In press).

Hughes, J.M.B., Glazier, J.B., Maloney, J.E. \& West, J.B. (1967) Effect of lung volume on the distribution of pulmonary blood flow in man. Respir. Physiol. 3, 216.

Milic-Emili, J., Henderson, J.A.M., Dolovich, M.B., TROP, D. \& KANEOKO, K. (1966) Regional distribution of inspired gas in the lung. J. appl. Physiol. 21, 749.

WEST, J.B. (1965) Ventilation/Blood Flow and Gas Exchange. Blackwell Scientific Publications, Oxford.

WeST, J.B. \& Dollery, C.T. (1960) Distribution of blood flow and ventilation-perfusion ratio in the lung, measured with radioactive $\mathrm{CO}_{2}$. J. appl. Physiol. 15, 405. 